\title{
Total lung capacity by plethysmography and high-resolution computed tomography in COPD
}

This article was published in the following Dove Press journal:

International Journal of COPD

21 February 2012

Number of times this article has been viewed

\author{
Jamie L Garfield \\ Nathaniel Marchetti \\ John P Gaughan \\ Robert M Steiner \\ Gerard J Criner \\ Department of Pulmonary and \\ Critical Care Medicine and \\ Department of Radiology, Temple \\ University School of Medicine, \\ Philadelphia, Pennsylvania, USA
}

Correspondence: Jamie L Garfield Temple University School of Medicine, Division of Pulmonary and Critical Care Medicine, 745 Parkinson Pavilion, 340 I North Broad Street, Philadelphia, PA 19140, USA

Tel +I 2157075864

Fax +I 2157076867

Email jamie.garfield@tuhs.temple.edu
Aim: To characterize and compare total lung capacity (TLC) measured by plethysmography with high-resolution computed tomography (HRCT), and to identify variables that predict the difference between the two modalities.

Methods: Fifty-nine consecutive patients referred for the evaluation of COPD were retrospectively reviewed. Patients underwent full pulmonary function testing and HRCT within 3 months. TLC was obtained by plethysmography as per American Thoracic Society/European Respiratory Society standards and by HRCT using custom software on 0.75 and $5 \mathrm{~mm}$ thick contiguous slices performed at full inspiration (TLC).

Results: TLC measured by plethysmography correlated with TLC measured by inspiratory HRCT $(r=0.92, P<0.01)$. TLC measured by plethysmography was larger than that determined by inspiratory HRCT in most patients (mean of $6.46 \pm 1.28 \mathrm{~L}$ and $5.34 \pm 1.20 \mathrm{~L}$ respectively, $P<0.05$ ). TLC measured by both plethysmography and HRCT correlated significantly with indices of airflow obstruction (forced expiratory volume in 1 second/forced vital capacity [FVC] and $\mathrm{FVC} \%$ ), static lung volumes (residual volume, percent predicted [RV\%], total lung capacity, percent predicted [TLC\%], functional residual capacity, percent predicted [FRC\%], and inspiratory capacity, percent predicted), and percent emphysema. TLC by plethysmography and HRCT both demonstrated significant inverse correlations with diffusion impairment. The absolute difference between TLC measured by plethysmography and HRCT increased as $\mathrm{RV} \%$, TLC\%, and FRC\% increased. Gas trapping (RV\% and FRC\%) independently predicted the difference in TLC between plethysmography and HRCT.

Conclusion: In COPD, TLC by plethysmography can be up to $2 \mathrm{~L}$ greater than inspiratory HRCT. Gas trapping independently predicts patients for whom TLC by plethysmography differs significantly from HRCT.

Keywords: lung capacity, plethysmography, high-resolution computed tomography, gas trapping, lung volume measurement errors

\section{Background}

Estimation of lung volume is used to help categorize the type, severity, and progression of lung diseases, and their response to therapy. ${ }^{1}$ The overestimation of total lung capacity (TLC) by body plethysmograpy compared with high-resolution computed tomography (HRCT) (or, as some see it, the underestimation by HRCT compared with plethysmography) is well described in the literature..$^{2-4}$ The degree to which TLC measured by body plethysmography differs from HRCT in COPD is not understood. This may have significant implications for determining patient eligibility for therapies such as lung volume reduction surgery, characterizing a prospective lung transplant recipient's lung volume dimensions, or assessing the response to treatment. ${ }^{5}$ Our objective was 
to describe the degree to which TLC determination by body plethysmography differs from HRCT. Further, we sought to identify variables that may predict this difference.

\section{Materials and methods Study patients}

A retrospective review was performed on 71 sequential patients referred to our outpatient clinic for the evaluation of COPD between September 2008 and December 2008. Patients who met the following criteria were extracted: (1) obstructive physiology evidenced by forced expiratory volume in 1 second $\left(\mathrm{FEV}_{1}\right)$ /forced vital capacity $(\mathrm{FVC}) \leq 70$ and $\mathrm{TLC} \leq 80$, (2) no or minimal radiographic abnormalities, or (3) complete pulmonary function tests (PFTs) and HRCT within 3 months.

\section{PFTs}

All patients underwent PFTs that were performed on a body plethysmograph (VMax Spectra 22D/62J; Carefusion, Yorba Linda, CA) according to the guidelines of the American Thoracic Society/European Respiratory Society. TLC was obtained as per American Thoracic Society/European Respiratory Society standards. ${ }^{6,7}$ Patients were excluded if they failed to meet criteria for reproducibility, which was defined as the patient demonstrating at least three functional residual capacity (FRC) $)_{\text {pleth }}$ values that agree within 5\% (two patients), or if they failed to perform three to five technically satisfactory panting maneuvers at frequencies at or around 1 Hertz (two patients).

\section{Chest HRCT}

HRCT scans with 0.75 and $5 \mathrm{~mm}$ contiguous slices were performed at full inspiration using a 16 or 64 MDCT scanner (Somatom Sensation; Siemens Medical Systems, Erlangen, Germany). Technical parameters included $\mathrm{kVp}$ of 100-120 determined by estimation of body mass index. Patients underwent helical computed tomography (CT) of the entire lung at maximum inspiration in the supine position. Patients received breathing instructions by recorded voice commands from the $\mathrm{CT}$ scanner. Custom software (Pulmonary Workstation Plus, VIDA Diagnostics, Inc, Coralville, IA) was used to determine total lung volume, tissue volume, and air volume in milliliters, and mean lung density in Hounsfield units (HU) for each patient. All voxels marked as lung parenchyma were analyzed. Percent emphysema was determined as the percentage of voxels below thresholds of -950 and $-910 \mathrm{HU}$. Total volume at full inspiration represents the TLC by HRCT for all analysis (Figure 1). HRCT scans were excluded from analysis for radiographic abnormalities other than emphysema including parenchymal consolidation, pleural effusion, and previous lung volume reduction surgery (LVRS) or transplant surgery (two patients). Patients were also excluded from analysis when the VIDA software was unable to process the scan

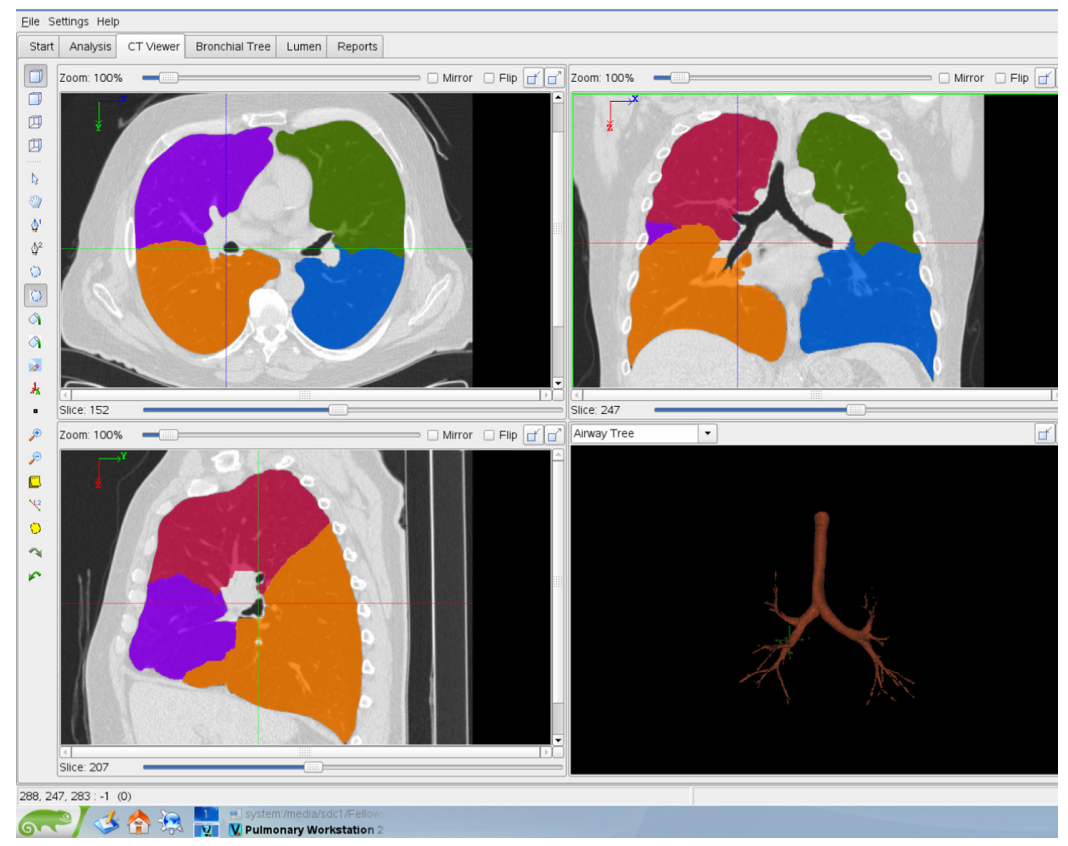

Figure I Diagram of the lungs of a 6I-year-old man with COPD. The transverse view (top left), coronal view (top right), and sagittal view (bottom left) are at the same anatomical level, as well as three-dimensional rendering of tracheobronchial tree (bottom right). 
due to technical difficulties, including failure to identify the tracheobronchial tree (six patients).

\section{Statistical analysis}

Student's $t$-test was used for comparison of TLC by plethysmography and HRCT. The Wilcoxon signed rank test was used where normality was not met. Spearman's rank order correlation and Bland-Altman analysis were used for comparison of TLC by plethysmography and HRCT. Multiple linear regressions were used to determine which variables accounted for the ability to predict the difference between TLC measured by plethysmography and HRCT. Data are presented as mean \pm standard deviation unless otherwise indicated.

\section{Results}

Demographics, pulmonary function data, and HRCT results obtained from the 59 patients are reported in Tables 1-3 respectively. Pulmonary function testing and HRCT were performed within $3 \pm 20$ days of each other. The subject population included 18 patients (31\%) with Global Initiative for Chronic Obstructive Lung Disease (GOLD) II disease, 22 patients (37\%) with GOLD III disease, and 19 patients (32\%) with GOLD IV disease. ${ }^{8}$

Total lung volume as measured by plethysmography correlated significantly with that measured by HRCT ( $r=0.92$, $P<0.01$ ) (Figure 2). TLC measured by plethysmography (average $6.46 \pm 1.28 \mathrm{~L}$ ) was larger than that determined by inspiratory HRCT $(5.34 \pm 1.20 \mathrm{~L})$ in most patients $(P<0.05)$. In Bland-Altman analysis, the average of the two measurements is thought to represent the "true value." As the true value increases the difference between the two modalities also increases (Figure 3 ). The mean TLC measured by plethysmography was $1.12 \mathrm{~L}$ greater than TLC measured by HRCT.

We found $\mathrm{FEV}_{1}$ to be significantly correlated with percent emphysema and mean lung density, a result which agrees with that reported by Baldi et al. ${ }^{9} \mathrm{FEV}_{1}$ was not significantly correlated with lung volume measured by plethysmography or HRCT, however, or with the difference between plethymography and HRCT (Table 4).

Table I Demographics in 59 patients with COPD

\begin{tabular}{lll}
\hline Variables & Mean & SD or \% total \\
\hline Age (years) & 63 & 9 \\
Male & 27 & $46 \%$ \\
Caucasian & 47 & $80 \%$ \\
BMl & 27 & 6 \\
Pack-years & 41 & 18 \\
\hline
\end{tabular}

Abbreviations: BMI, body mass index; pack-years, packs of tobacco smoked per day $\times$ years as a smoker; $S D$, standard deviation.
Table 2 Pulmonary function in 59 patients with COPD

\begin{tabular}{|c|c|c|}
\hline Variables & Mean & SD \\
\hline $\mathrm{FEV} / \mathrm{FVC}$ & 0.36 & 0.12 \\
\hline FVC (L) & 2.98 & 0.94 \\
\hline FVC\% & 85 & 17 \\
\hline $\mathrm{FEV}_{1}(\mathrm{~L})$ & 1.08 & 0.52 \\
\hline $\mathrm{FEV}, \%$ & 41 & 18 \\
\hline FEF $25-75(\mathrm{~L})$ & 0.61 & 0.23 \\
\hline FEF $25 \%-75 \%$ & 29 & 20 \\
\hline $\mathrm{RV}(\mathrm{L})$ & 3.38 & 1.0 \\
\hline $\mathrm{RV} \%$ & 164 & 48 \\
\hline TLC (L) & 6.46 & 1.28 \\
\hline TLC\% & 115 & 15 \\
\hline $\mathrm{RV} / \mathrm{TLC}$ & 0.52 & 0.11 \\
\hline FRC (L) & 4.44 & 1.08 \\
\hline FRC\% & 146 & 32 \\
\hline IC (L) & 2.02 & 0.73 \\
\hline IC\% & 86 & 22 \\
\hline IC/TLC & 0.31 & 0.09 \\
\hline DLCO/VA & 2.49 & 0.78 \\
\hline DLCO/VA\% & 50 & 15 \\
\hline
\end{tabular}

Abbreviations: DLCO/VA, carbon monoxide diffusing capacity corrected for alveolar volume; DLCO/VA\%, carbon monoxide diffusing capacity corrected for alveolar volume, percent predicted; FEF 25-75(L), forced expiratory volume during midexpiratory flow; FEF $25 \%-75 \%$, forced expiratory volume during midexpiratory flow, percent predicted; $\mathrm{FEV}_{\text {, }}$, forced expiratory volume in I second; $\mathrm{FEV}_{1} \%$, forced expiratory volume in I second, percent predicted; FRC, functional residual capacity; FVC, forced vital capacity; FVC\%, forced vital capacity, percent predicted; IC, inspiratory capacity; RV, residual volume; RV\%, residual volume, percent predicted; SD, standard deviation; TLC, total lung capacity; TLC\%, total lung capacity, percent predicted.

As has been reported by others, ${ }^{10-13}$ there was fair correlation between TLC measured by both plethysmography and $\mathrm{HRCT}$ with indices of airflow obstruction $\left(\mathrm{FEV}_{1} / \mathrm{FVC}\right.$ and $\mathrm{FVC} \%$ ), static lung volumes (residual volume, percent predicted $[\mathrm{RV} \%]$, total lung capacity, percent predicted [TLC\%], functional residual capacity, percent predicted [FRC\%], inspiratory capacity, percent predicted), and percent emphysema. Both TLC by plethysmography and HRCT showed weak but significant inverse correlations with diffusion impairment (Table 5).

The difference between TLC as measured by plethysmograhpy and HRCT correlated significantly with static

Table 3 HRCT in 59 patients with COPD

\begin{tabular}{lll}
\hline Variables & Mean & SD \\
\hline HRCT total volume (L) & 6.05 & 1.26 \\
HRCT tissue volume (L) & 0.71 & 0.16 \\
HRCT air volume (L) & 5.34 & 1.20 \\
HRCT density (HU) & -873.15 & 29.47 \\
Emphysema less than -950 (\%) & 27.74 & 14.9 \\
Emphysema less than -910 (\%) & 50.54 & 16.23 \\
\hline
\end{tabular}

Abbreviations: Emphysema less than -950, percent of voxels with Hounsfield units less than -950; emphysema less than -910 , percent of voxels with Hounsfield units less than -910 ; HRCT, high-resolution computed tomography; HU, Hounsfield units; SD, standard deviation. 


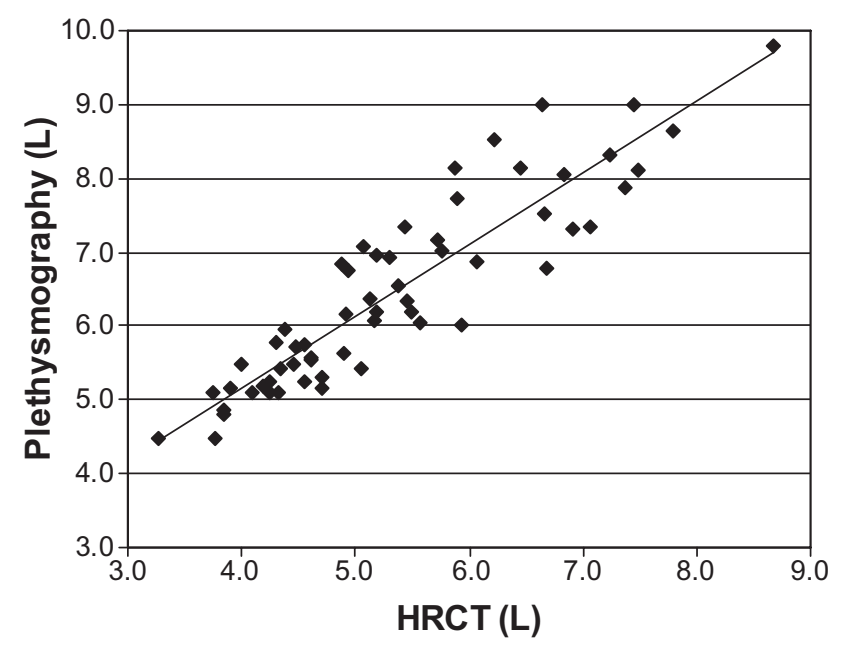

Figure 2 Correlation between inspiratory lung volume by HRCT and TLC derived from PFT results.

Notes: $r=0.92, P<0.01$.

Abbreviations: $\mathrm{HRCT}$, high-resolution computed tomography; TLC, total lung capacity.

lung volumes (RV\%, TLC\%, and FRC\%) (Table 5, Figures 4 and 5). In patients with more severe air trapping and hyperinflation, the difference between TLC measured by plethysmography and that determined by HRCT increased. Using multiple linear regressions, RV\% and FRC\% independently predicted the differences between TLC measured by plethysmography and HRCT (Table 6).

\section{Discussion}

Thoracic gas volume (TGV) can be measured in several different ways. In patients with COPD, body plethysmography is usually preferred to nitrogen washout and gas dilution techniques because it is argued that the latter methods are

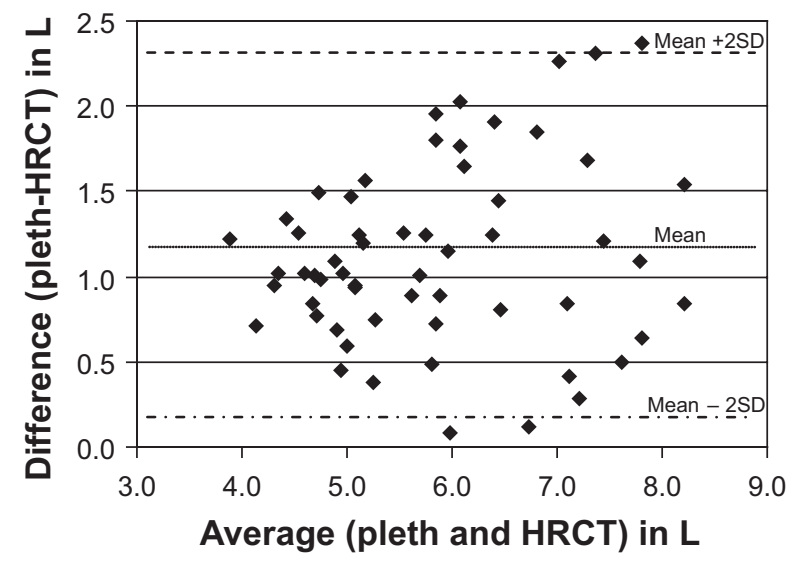

Figure 3 This plot of the difference between the methods against their mean illustrates the relationship between the measurement error and the true value. Total lung capacity measured by plethysmography is $1.12 \mathrm{~L}$ greater than total lung capacity measured by HRCT. Greater variation from the mean is seen at higher lung volumes, suggesting measurement error is greater at higher lung volumes.

Abbreviations: HRCT, high-resolution computed tomography; pleth, plethysmography.
Table 4 Comparison of FEV $\%$ with plethysmography and HRCT

\begin{tabular}{lll}
\hline Variables & FEV, $\%$ & \\
\cline { 2 - 3 } & $\boldsymbol{r}$ & $\boldsymbol{P}$ \\
\hline Plethysmography & -0.25 & 0.06 \\
Plethysmography-HRCT & 0.05 & 0.7 I \\
HRCT total (L) & -0.22 & 0.10 \\
HRCT tissue (L) & 0.26 & 0.05 \\
HRCT air (L) & -0.29 & 0.03 \\
HRCT density (HU) & 0.48 & 0.00 \\
Emphysema less than -950 (\%) & -0.43 & 0.00 \\
Emphysema less than -910 (\%) & -0.49 & 0.00 \\
\hline Abbrevitions
\end{tabular}

Abbreviations: $\mathrm{FEV}_{1}$, forced expiratory volume in I second; $\mathrm{RV}$, residual volume; FRC, functional residual capacity; FVC, forced vital capacity; HRCT, high-resolution computed tomography; TLC, total lung capacity.

unable to measure poorly ventilated or unventilated areas of the lung. ${ }^{14-16}$ While body plethysmography readily measures trapped air not in communication with the airways, it is not without its own inherent errors, particularly in patients with increased airway resistance. TGV is calculated using Boyle's law which states that pressure and volume are inversely proportional when temperature is constant. Within the body box, pressure at the mouth may not reflect true pressure in the alveoli if airway resistance increases. ${ }^{17,18}$ If alveolar pressure is underestimated, thoracic gas volume will be overestimated. Rodenstein et al demonstrated this error in the measurement of lung volumes by plethysmography when airflow obstruction occurs, and found thoracic gas volume measured from pressure swings at the mouth (TGVm) to be 1 or more liters greater than thoracic gas volume measured from pressure swings in the esophagus (TGVes), an indirect measurement of pleural pressure. ${ }^{19}$ The authors went on to qualify this overestimation of TGV in the setting of airflow obstruction as being dependent on panting frequency. ${ }^{20}$ TGVm was $1 \mathrm{~L}$ greater than TGVes at panting frequencies of $2 \mathrm{~Hz}$ in asthmatics, while no difference was seen in those without asthma. At higher frequencies, the discrepancy further increased in asthmatics, again with no difference in those without asthma. At lower panting frequencies, no difference was found between the two groups. ${ }^{21}$ This relationship between panting frequency and the overestimation of lung volume by plethysmography has also been described in patients with COPD. ${ }^{22,23}$

HRCT is an important method for routine testing for COPD. With dedicated post-processing software, rapid and reproducible estimates of tissue and air volume, mean lung density, percent emphysema, and airway anatomy are now available. ${ }^{24,25}$ Standardized computer-generated HRCT instructions have improved reproducibility and accuracy. ${ }^{26,27}$ 
Table 5 Correlation coefficients for plethysmography, HRCT, and the difference between plethysmography and HRCT

\begin{tabular}{|c|c|c|c|c|c|c|}
\hline \multirow[t]{2}{*}{ Variables } & \multicolumn{2}{|c|}{ Plethysmography } & \multicolumn{2}{|c|}{ HRCT } & \multicolumn{2}{|c|}{ Plethysmography-HRCT } \\
\hline & $\boldsymbol{r}$ & $P$ & $r$ & $P$ & $\boldsymbol{r}$ & $\mathbf{P}$ \\
\hline$\overline{\mathrm{FEV}} / \mathrm{FVC}$ & -0.39 & 0.00 & -0.35 & 0.01 & 0.02 & 0.88 \\
\hline FVC (L) & 0.58 & 0.00 & 0.66 & 0.00 & 0.03 & 0.84 \\
\hline FVC\% & 0.06 & 0.65 & 0.02 & 0.87 & 0.11 & 0.40 \\
\hline $\mathrm{FEV}_{\text {, }}(\mathrm{L})$ & 0.06 & 0.63 & 0.14 & 0.28 & 0.04 & 0.77 \\
\hline $\mathrm{FEV}_{\mathrm{I}} \%$ & -0.25 & 0.06 & -0.22 & 0.10 & 0.05 & 0.71 \\
\hline FEF 25-75 (L) & 0.09 & 0.57 & 0.08 & 0.69 & 0.07 & 0.80 \\
\hline FEF $25 \%-75 \%$ & -0.30 & 0.05 & -0.27 & 0.06 & 0.12 & 0.39 \\
\hline $\mathrm{RV}(\mathrm{L})$ & 0.69 & 0.00 & 0.54 & 0.00 & 0.32 & 0.02 \\
\hline RV\% & 0.44 & 0.00 & 0.28 & 0.03 & 0.29 & 0.03 \\
\hline TLC (L) & - & - & 0.90 & 0.00 & 0.31 & 0.02 \\
\hline TLC\% & 0.56 & 0.00 & 0.34 & 0.00 & 0.39 & 0.00 \\
\hline $\mathrm{RV} / \mathrm{TLC}$ & 0.07 & 0.60 & -0.06 & 0.67 & 0.16 & 0.21 \\
\hline FRC (L) & 0.85 & 0.00 & 0.74 & 0.00 & 0.29 & 0.03 \\
\hline $\mathrm{FRC} \%$ & 0.48 & 0.00 & 0.33 & 0.01 & 0.27 & 0.04 \\
\hline IC (L) & 0.38 & 0.00 & 0.43 & 0.00 & 0.04 & 0.78 \\
\hline IC\% & -0.02 & 0.87 & -0.06 & 0.67 & 0.07 & 0.60 \\
\hline IC/TLC & -0.13 & 0.33 & -0.05 & 0.72 & -0.07 & 0.61 \\
\hline DLCO/VA & -0.42 & 0.00 & -0.35 & 0.01 & -0.06 & 0.63 \\
\hline DLCO/VA\% & -0.42 & 0.00 & -0.35 & 0.01 & -0.05 & 0.71 \\
\hline HRCT total (L) & 0.90 & 0.00 & - & - & -0.06 & 0.64 \\
\hline HRCT tissue $(\mathrm{L})$ & 0.39 & 0.00 & 0.52 & 0.00 & 0.10 & 0.43 \\
\hline HRCT air $(\mathrm{L})$ & 0.92 & 0.00 & 0.98 & 0.00 & -0.08 & 0.56 \\
\hline HRCT density $(\mathrm{HU})$ & -0.44 & 0.00 & -0.39 & 0.00 & 0.20 & 0.13 \\
\hline$\%$ emphysema less than -950 & 0.43 & 0.00 & 0.41 & 0.00 & -0.18 & 0.18 \\
\hline$\%$ emphysema less than -910 & 0.49 & 0.00 & 0.44 & 0.00 & -0.15 & 0.26 \\
\hline
\end{tabular}

Abbreviations: DLCO/VA, carbon monoxide diffusing capacity corrected for alveolar volume; DLCO/VA\%, carbon monoxide diffusing capacity corrected for alveolar volume, percent predicted; emphysema less than -950 , percent of voxels with Hounsfield units less than -950; emphysema less than -910, percent of voxels with Hounsfield units less than -910; FEF 25-75(L), forced expiratory volume during midexpiratory flow; FEF $25 \%-75 \%$, forced expiratory volume during midexpiratory flow, percent predicted; $\mathrm{FEV}_{1}$, forced expiratory volume in I second; $\mathrm{FEV}_{1} \%$, forced expiratory volume in I second, percent predicted; FRC, functional residual capacity; FVC, forced vital capacity; FVC\%, forced vital capacity, percent predicted; HRCT, high-resolution computed tomography; HU, Hounsfield units; IC, inspiratory capacity; RV, residual volume; RV\%, residual volume, percent predicted; TLC, total lung capacity; TLC\%, total lung capacity, percent predicted.

Lung volume measurement by HRCT remains fraught with predictable and unpredictable errors. ${ }^{28}$ Supine positioning during HRCT results in a reduction in the size of the various subdivisions of the lung. ${ }^{29-32}$ In normal subjects, vital capacity (VC) falls less than $10 \%$ when passing from the upright to the supine position, ${ }^{33,34}$ but a reduction of up to $25 \%$ has been described in patients with diaphragm dysfunction and respiratory muscle weakness, conditions commonly seen in patients with COPD. ${ }^{35}$ However, postural changes in $\mathrm{VC}$ in patients with COPD have not been well described. Unpredictable errors in the measurement of lung volumes by HRCT include difficulty with maximum inspiratory maneuvers and breath-holding techniques during scanning. ${ }^{36}$ Using spirometric gating, patients with severe airflow obstruction have not been shown to reproducibly achieve maximum inspiratory volumes during HRCT. ${ }^{37}$

In similar patient populations, previous authors have shown strong correlations between TLC measured by plethysmography and HRCT (Zaporozhan et al, Coxson et al, and Gierada et al reported $r=0.90,0.88$, and 0.87 , respectively). ${ }^{2-4}$ Given what we know about the limitations of plethysmography and HRCT in COPD, we expected to find a relationship between severity of airflow obstruction and the differences in the measurement of TLC between plethsmography and HRCT. If TLC by plethysmography is potentially overestimated in the setting of increased airway resistance, we postulated that as $\mathrm{FEV}_{1}$ decreased there would be greater differences between TLC measured by plethysmography and HRCT. We further hypothesized that increased airways resistance and subsequent air trapping and hyperinflation ${ }^{38}$ would be associated with the overestimation of lung volumes by plethysmography. A recent paper by O'Donnell et al compared lung volumes by plethysmography and helium dilution with HRCT in COPD, ${ }^{39}$ with plethysmographic TLC found to be significantly greater than HRCT values, and plethysmographic overestimation of TLC reported to be greatest among subjects with FEV $<30 \%$ of predicted. This was not found to be the case in the current study as differences between TLC measured by 


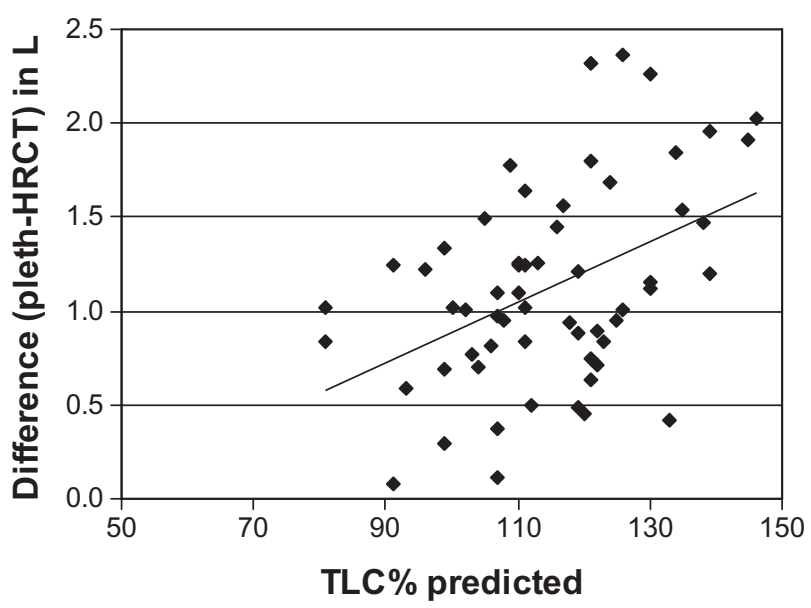

Figure 4 Relationship between TLC\% predicted and difference between lung volumes determined by plethysmography (pleth) and HRCT.

Notes: $r=0.39, P<0.01$.

Abbreviations: HRCT, high-resolution computed tomography; TLC\%, total lung capacity, percent.

plethysmography and HRCT did not change across GOLD stages. This relationship between airflow obstruction and the plethysmographic overestimation of TLC may not have been seen because the current study's population included a range of $\mathrm{FEV}_{1}$ from normal to very severe, and may not be powered sufficiently for subgroup analysis among patients with very severe airflow obstruction. O'Donnell et al collected data from subjects at three hospitals where HRCT and plethysmographic technique may not have been standardized. Patients recruited from one of the hospitals undergoing evaluation for LVRS had substantially lower average $\mathrm{FEV}_{1}$ than those from the other two hospitals. Subtle differences in HRCT and plethysmographic technique at this hospital may have driven

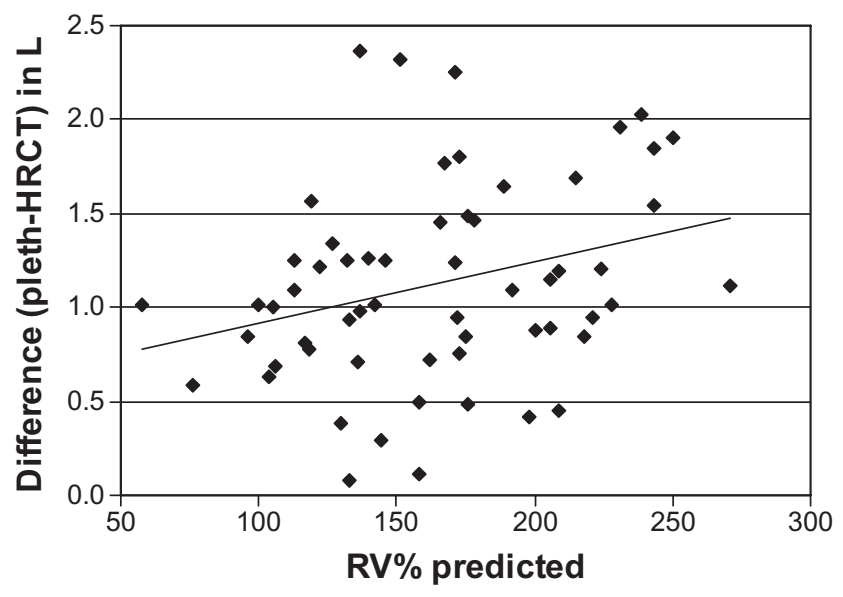

Figure 5 Relationship between RV\% predicted and difference between lung volumes determined by plethysmography (pleth) and HRCT.

Notes: $r=0.29, P<0.01$.

Abbreviations: HRCT, high-resolution computed tomography; RV\%, residual volume, percent.
Table 6 Multiple linear regressions

\begin{tabular}{lll}
\hline Variables & \multicolumn{2}{l}{ Plethysmography-HRCT } \\
\cline { 2 - 3 } & $\boldsymbol{t}$ & $\boldsymbol{P}$ \\
\hline RV\% & -2.14 & 0.04 \\
TLC\% & -0.88 & 0.39 \\
RV/TLC & 0.15 & 0.88 \\
FRC\% & 2.33 & 0.03
\end{tabular}

Abbreviations: $F R C \%$, functional residual capacity, percent predicted; HRCT, high-resolution computed tomography; RV, residual volume; RV\% residual volume, percent predicted; TLC, total lung capacity; TLC\%, total lung capacity, percent predicted.

the relationship between airflow obstruction and the overestimation of plethysmographic TLC. Our data were collected at a single center and our methodology was standardized for all patients. No mention was made by O'Donnell et al as to the effect of hyperinflation and air trapping on lung volume determination. Our data suggest that more significant air trapping (RV\% and $\mathrm{FRC} \%$ ) and hyperinflation (TLC\%) is present in the COPD patients with the greatest difference in TLC measured by plethsmography and HRCT.

Limitations in our study include lack of spirometric gating during image acquisition with HRCT. Sub-maximal inspiratory maneuvers would have resulted in an underestimation of TLC by HRCT compared to plethysmography. Another limitation of our study is that the pulmonary function tests were not necessarily performed on the same day as the HRCT, weakening the correlation between these modalities.

Understanding the variability with which TLC by plethysmography differs from HRCT has important implications in the evaluation of patients with COPD. Global and regional measurements of lung volumes can be important in identifying patients who are most likely to benefit from LVRS. ${ }^{40}$ Similarly, precise volume determination is necessary to accurately identify suitable donor and recipient lungs for transplantation. ${ }^{5}$ Finally, the ability to precisely measure lung volume may be central to determining the importance of hyperinflation in COPD, and the impact of therapies geared to reducing end-expiratory lung volumes.

\section{Conclusion}

Total lung capacity measured by plethysmography is larger than that determined by HRCT in COPD. The degree to which TLC measured by plethysmography differs from that determined by HRCT is correlated with air trapping and hyperinflation. $\mathrm{RV} \%$ and $\mathrm{FRC} \%$ predict the difference between TLC determined by plethysmography and HRCT. 
The method used to obtain TLC in severely hyperinflated patients needs to be considered when precise measurements are required for clinical decision making.

\section{Acknowledgments and disclosure}

This retrospective review was designed and executed by Dr Garfield. The manuscript was written by Dr Garfield and edited by Drs Marchetti and Criner. The authors have no disclosures or conflicts of interest to report with regard to the material put forth in this manuscript. This study was partially funded by the Pennsylvania Department of Health PA-DOH 02-70-02.

\section{References}

1. Pellegrino R, Viegi G, Brusasco V, et al. Interpretative strategies for lung function tests. Eur Respir J. 2005;26(5):948-968.

2. Coxson HO, Nasute Fauerbach PV, Storness-Bliss C, et al. Computed tomography assessment of lung volume changes after bronchial valve treatment. Eur Respir J. 2008;32(6):1443-1450.

3. Gierada DS, Hakimian S, Slone RM, Yusen RD. MR analysis of lung volume and thoracic dimensions in patients with emphysema before and after lung volume reduction surgery. AJR Am J Roentgenol. 1998;170(3):707-714.

4. Zaporozhan J, Ley S, Eberhardt R, et al. Paired inspiratory/expiratory volumetric thin-slice CT scan for emphysema analysis: Comparison of different quantitative evaluations and pulmonary function test. Chest. 2005;128(5):3212-3220

5. Orens JB, Estenne M, Arcasoy S, et al. International guidelines for the selection of lung transplant candidates: 2006 update - a consensus report from the Pulmonary Scientific Council of the International Society for Heart and Lung Transplantation. J Heart Lung Transplant. 2006;25(7):745-755.

6. Pauwels RA, Buist AS, Ma P, Jenkins CR, Hurd SS; GOLD Scientific Committee. Global strategy for the diagnosis, management, and prevention of chronic obstructive pulmonary disease: National Heart, Lung, and Blood Institute and World Health Organization Global Initiative for Chronic Obstructive Dung Disease (GOLD): executive summary. Respir Care. 2001;46(8):798-825.

7. Wanger J, Clausen JL, Coates A, et al. Standardisation of the measurement of lung volumes. Eur Respir J. 2005;26(3):511-522.

8. Global Initiative for Chronic Obstructive Lung Disease (GOLD). Global Strategy for the Diagnosis, Management and Prevention of COPD. GOLD, Inc; 2011. Available from: http://www.goldcopd. org/uploads/users/files/GOLD_Report_2011_Jan21.pdf. Accessed January 31, 2012.

9. Baldi S, Miniati M, Bellina CR, et al. Relationship between extent of pulmonary emphysema by high-resolution computed tomography and lung elastic recoil in patients with chronic obstructive pulmonary disease. Am J Respir Crit Care Med. 2001;164(4):585-589.

10. Spiropoulos K, Trakada G, Kalamboka D, et al. Can high resolution computed tomography predict lung function in patients with chronic obstructive pulmonary disease? Lung. 2003;181(4):169-181.

11. Akira M, Toyokawa K, Inoue $\mathrm{Y}$, Arai T. Quantitative $\mathrm{CT}$ in chronic obstructive pulmonary disease: inspiratory and expiratory assessment. AJR Am J Roentgenol. 2009;192(1):267-272.

12. Lee YK, Oh YM, Lee JH, et al; KOLD Study Group. Quantitative assessment of emphysema, air trapping, and airway thickening on computed tomography. Lung. 2008;186(3):157-165.

13. Kauczor HU, Hast J, Heussel CP, Schlegel J, Mildenberger P, Thelen M. CT attenuation of paired HRCT scans obtained at full inspiratory/ expiratory position: comparison with pulmonary function tests. Eur Radiol. 2002;12(11):2757-2763.
14. Ries AL. Measurement of lung volumes. Clin Chest Med. 1989;10(2): 177-186.

15. Rodenstein DO, Stänescu DC. Reassessment of lung volume measurement by helium dilution and by body plethysmography in chronic air-flow obstruction. Am Rev Respir Dis. 1982;126(6):1040-1044.

16. Schaanning CG, Gulsvik A. Accuracy and precision of helium dilution technique and body plethysmography in measuring lung volumes. Scand J Clin Lab Invest. 1973;32(3):271-277.

17. Brown R, Hoppin FG Jr, Ingram RH Jr, Saunders NA, McFadden ER Jr. Influence of abdominal gas on the Boyle's law determination of thoracic gas volume. J Appl Physiol. 1978;44(3):469-473.

18. Brown R, Ingram RH Jr, McFadden ER Jr. Problems in the plethysmographic assessment of changes in total lung capacity in asthma. Am Rev Respir Dis. 1978;118(4):685-692.

19. Rodenstein DO, Stänescu DC, Francis C. Demonstration of failure of body plethysmography in airway obstruction. J Appl Physiol. 1982; 52(4):949-954.

20. Stänescu DC, Rodenstein D, Cauberghs M, Van de Woestijne KP. Failure of body plethysmography in bronchial asthma. J Appl Physiol. 1982;52(4):939-948.

21. Rodenstein DO, Stänescu DC. Frequency dependence of plethysmographic volume in healthy and asthmatic subjects. J Appl Physiol. 1983;54(1):159-165.

22. Brown R, Slutsky AS. Frequency dependence of plethysmographic measurement of thoracic gas volume. J Appl Physiol. 1984;57(6): $1865-1871$.

23. Shore SA, Huk O, Mannix S, Martin JG. Effect of panting frequency on the plethysmographic determination of thoracic gas volume in chronic obstructive pulmonary disease. Am Rev Respir Dis. 1983;128(1): 54-59.

24. Gupta PP, Yadav R, Verma M, Agarwal D, Kumar M. Correlation between high-resolution computed tomography features and patients' characteristics in chronic obstructive pulmonary disease. Ann Thorac Med. 2008;3(3):87-93.

25. Kinsella M, Müller NL, Abboud RT, Morrison NJ, DyBuncio A. Quantitation of emphysema by computed tomography using a "density mask" program and correlation with pulmonary function tests. Chest. 1990;97(2):315-321.

26. Camiciottoli G, Bartolucci M, Maluccio NM, et al. Spirometrically gated high-resolution CT findings in COPD: Lung attenuation vs lung function and dyspnea severity. Chest. 2006;129(3):558-564.

27. Bankier AA, O'Donnell CR, Boiselle PM. Quality initiatives. Respiratory instructions for CT examinations of the lungs: a hands-on guide. Radiographics. 2008;28(4):919-931.

28. Hu S, Hoffman EA, Reinhardt JM. Automatic lung segmentation for accurate quantitation of volumetric X-ray CT images. IEEE Trans Med Imaging. 2001;20(6):490-498.

29. Hurtado A, Boller C. Studies of total pulmonary capacity and its sub-divisions. I. Normal, absolute and relative values. J Clin Invest. 1933;12(5):793-806.

30. Hurtado A, Fray WW. Studies of total pulmonary capacity and its subdivisions. II. Correlation with physical and radiological measurements. J Clin Invest. 1933;12(5):807-823.

31. Hurtado A, Fray WW. Studies of total pulmonary capacity and its subdivisions. III. Changes with body posture. J Clin Invest. 1933;12(5): 825-832.

32. Watson RA, Pride NB. Postural changes in lung volumes and respiratory resistance in subjects with obesity. J Appl Physiol. 2005;98(2): 512-517.

33. Blair E, Hickam JB. The effect of change in body position on lung volume and intrapulmonary gas mixing in normal subjects. $J$ Clin Invest. 1955;34(3):383.

34. Allen SM, Hunt B, Green M. Fall in vital capacity with posture. $\mathrm{Br} J$ Dis Chest. 1985;79(3):267-271.

35. Fromageot C, Lofaso F, Annane D, et al. Supine fall in lung volumes in the assessment of diaphragmatic weakness in neuromuscular disorders. Arch Phys Med Rehabil. 2001;82(1):123-128. 
36. Kauczor HU, Heussel CP, Fischer B, Hast J, Mildenberger P, Thelen M. Value of spirometry-gated high resolution computerized tomography of the lung during inspiration and expiration [article in German]. Rofo. 1998;169(6):658-661.

37. Moroni C, Mascalchi M, Camiciottoli G, et al. Comparison of spirometric-gated and -ungated HRCT in COPD. J Comput Assist Tomogr. 2003;27(3):375-379.

38. Leith DE, Brown R. Human lung volumes and the mechanisms that set them. Eur Respir J. 1999;13(2):468-472.
39. O’Donnell CR, Bankier AA, Stiebellehner L, Reilly JJFCCP, Brown R, Loring SH. Comparison of plethysmographic and helium dilution lung volumes: which is best for COPD? Chest. 2010;137(5): 1108-1115.

40. Becker MD, Berkmen YM, Austin JH, et al. Lung volumes before and after lung volume reduction surgery: quantitative CT analysis. Am J Respir Crit Care Med. 1998;157(5 Pt 1):1593-1599.

\section{Publish your work in this journal}

The International Journal of COPD is an international, peer-reviewed journal of therapeutics and pharmacology focusing on concise rapid reporting of clinical studies and reviews in COPD. Special focus is given to the pathophysiological processes underlying the disease, intervention programs, patient focused education, and self management protocols.

\section{Dovepress}

This journal is indexed on PubMed Central, MedLine and CAS. The manuscript management system is completely online and includes a very quick and fair peer-review system, which is all easy to use. Visit http://www.dovepress.com/testimonials.php to read real quotes from published authors. 